\title{
STUDY OF THIN FILM STRUCTURES FOR USES IN ANEMOMETRY
}

\author{
Lucian Bogatu1, Georgeta Ionascu², Elena Manea ${ }^{3}$ \\ 1,2 Politehnica University of Bucharest \\ 313, Splaiul Independentei, 060042-Bucharest, Romania \\ ${ }^{3}$ National Institute for Research and Development in Microtechnologies \\ 126A, Erou Iancu Nicolae Street, 077190-Bucharest, Romania \\ lbogatu@yahoo.com, ionascu georgeta@yahoo.com, elena.manea@imt.ro
}

\begin{abstract}
A thin film structure consisting in a spiral shaped (coiled) trace of copper, carried out on a flexible PCB (Printed Circuit Board) foil is studied in this paper, as sensible element of a hot-film anemometer. The dimensions of the structure are $19 \times 6 \mathrm{~mm} 2$, with lines and gaps of $50 \mu \mathrm{m}$ width and, respectively, $18 \mu \mathrm{m}$ height (thickness of the copper film), laminated on a polyimide substrate of $12.5 \mu \mathrm{m}$ thickness. The assembly was bonded with a thin and uniform layer of cyanoacrylate glue on a uncovered FR 4 PCB of $0.5 \mathrm{~mm}$. The configuration of this structure has been made through a photochemical machining process, also known as photoetching or selective chemical erosion using a photoresist mask. An original installation was used to calibrate the new considered structure and the sensor characteristic was determined.
\end{abstract}

Keywords: Hot-film anemometer, Sensor, Structure of copper thin film, Flexible printed circuit board, Microfabrication, calibration.

\section{Introduction}

A hot-wire or hot-film anemometer is a device used for measuring velocity of fluid whose applications can be found in meteorology, wind energy [1], in fluid flow study through pipelines or around various bodies, in the study of air currents from an enclosure or in flow measurements (to measure the fluid flow passing through a pipe) [2-6]. This device is based on changing of certain thermal characteristics of a sensible element, which is exposed to flowing fluids.

The main element of a hot-wire or hot-film anemometer is the sensor (the heating resistive sensible element).

The measuring principle of a hot-wire or hot-film anemometer relies on three processes:

1. the change of temperature of the sensor when the fluid velocity is modified, as a consequence of the complex heat transfer between the sensible element (which is electrically heated at a temperature higher than the fluid one) and the fluid in which this is immersed; the complex heat transfer takes place: a) through conduction, under a static or dynamic condition, inside the sensible element and between this one and its support; b) through convection between the sensible element and the fluid, and c) through radiation between the sensible element, the fluid and the adjacent bodies;

2. the change of sensible element resistance when modifying its temperature;

3. the change of voltage or of current intensity in the circuit attached to the sensible element, when its resistance modifies.

The first two processes take place strictly at the level of the sensible element, while the third one takes place at the level of the adapting block.

The final result is the dependence of fluid velocity on the voltage or current intensity. In this case, the voltage or current intensity is the modulated quantities (amplitude is the modulated parameter). This is the metrological signal.

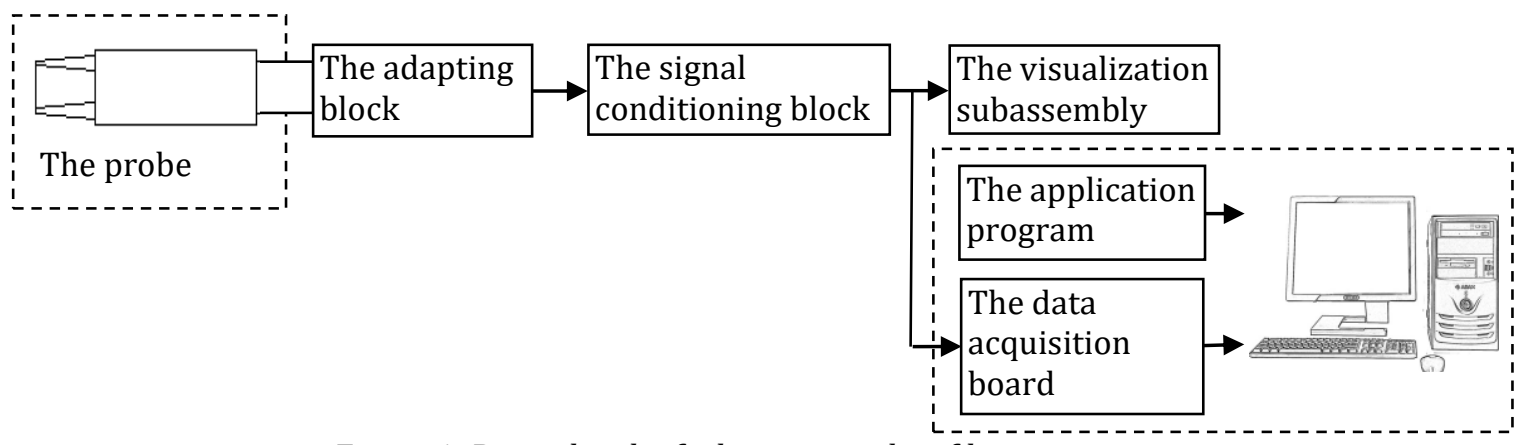

Figure 1: Basic sketch of a hot-wire or hot-film anemometer 


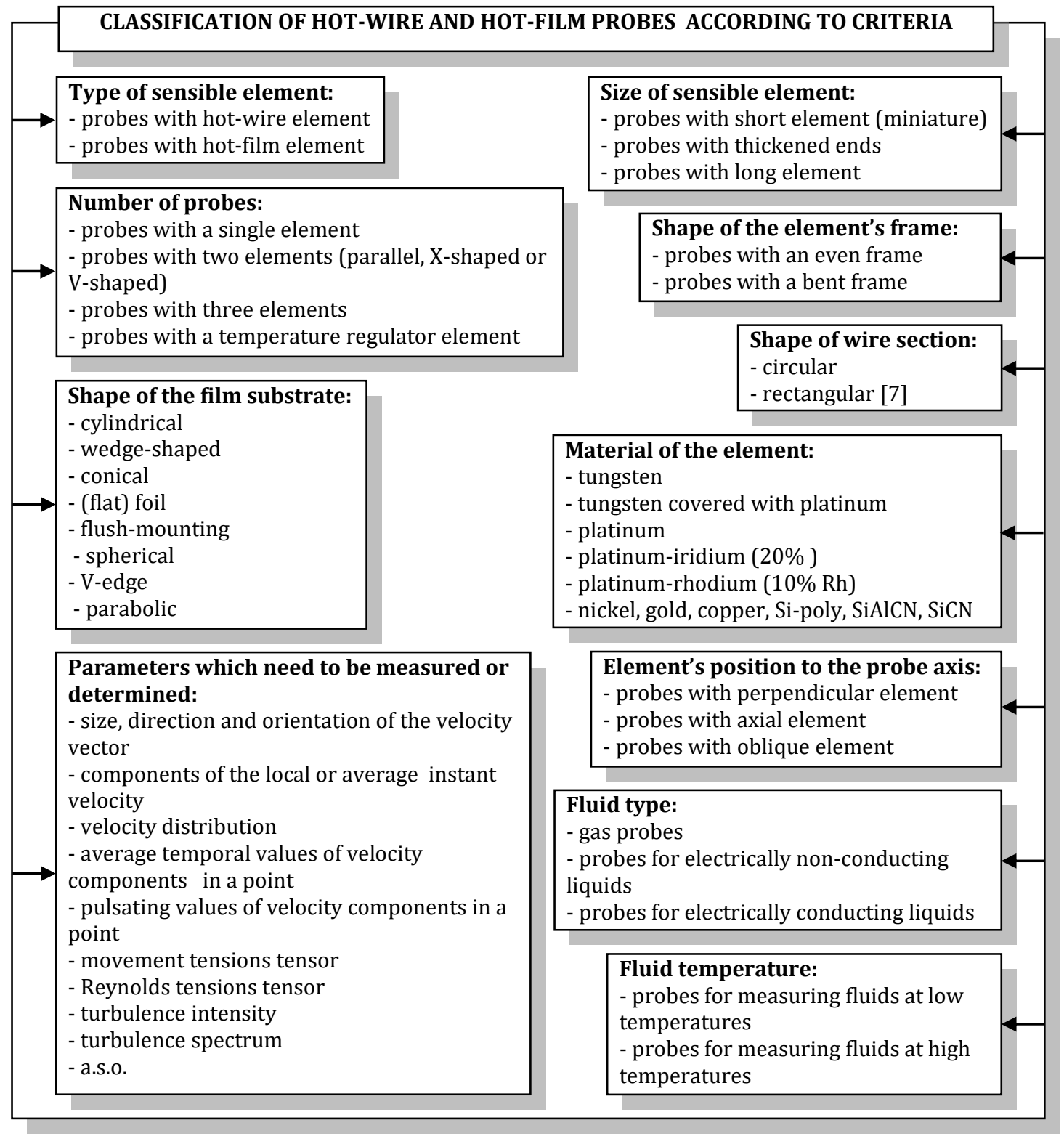

Figure 2: General classification of hot-wire and hot-film probes

In figure 1 , the basic diagram of a hot element anemometer is presented, as follows: the probe (velocity transducer) with the sensor (resistive hotwire or hot-film sensible element); the adapting block, represented by an electrical circuit through which the metrological signal (voltage or intensity) is modulated; the signal conditioning block consisting of a linearization circuit, filters, amplifiers, correlation circuit, spectral analyzer etc.; the visualization subassembly, which can be made of an analogue or digital voltmeter, an oscilloscope, a recorder etc.; the data acquisition system, which consists of the data acquisition board, the computer and the application program.

A classification of hot-wire and hot-film probes of anemometers can be made according to the criteria given in figure 2. After the way the adapting block works, anemometers are of three types: of constant temperature (resistance) - CTA, constant electric intensity, and constant voltage. Rectangular hot-wire
[7] and hot-film probes [8-11] were created because a greater sensitivity is obtained due to an increased heat transfer.

A hot-element type sensor must have two characteristics to make it a useful device:

- a high temperature coefficient of resistance;

- an electrical resistance such that it can be easily heated with an electrical current at practical voltage and current levels.

The most common wire materials are metals such as tungsten, platinum and platinumiridium/rhodium alloys, or semiconductor (doped polycrystalline silicon) and ceramics like the polymer-derived ceramic (PDC) material class.

The hot-film sensor is essentially a conducting film deposited on a dielectric (flexible) substrate: platinum, gold, nickel, copper, using chromium or titanium as intermediate adherence layer, deposited on substrate of polyimide, kapton and parylene. Among the metals, copper shows interest because its 
useful properties, as well: good electrical conductivity, good thermal conductivity, corrosion resistance, easily joined, ductile and tough at the same time. Copper allows heat to pass through it quickly.

It is therefore used in many applications where quick heat transfer is important, as is the case of anemometry too. In addition, copper is available as a laminated layer on a thin insulating polymer film, commonly used in the printed circuit board (PCB) technology, which involves a cheap achieving process compared to the other materials deposited through expensive methods of thin film technology.

\section{The Calibration Installation}

Previous accomplishments include design and implementation of a calibration installation of velocity transducers and development of program that manages data acquisition and processing. The calibration method is based on a convergent nozzle, in top of which the velocity transducer is placed.

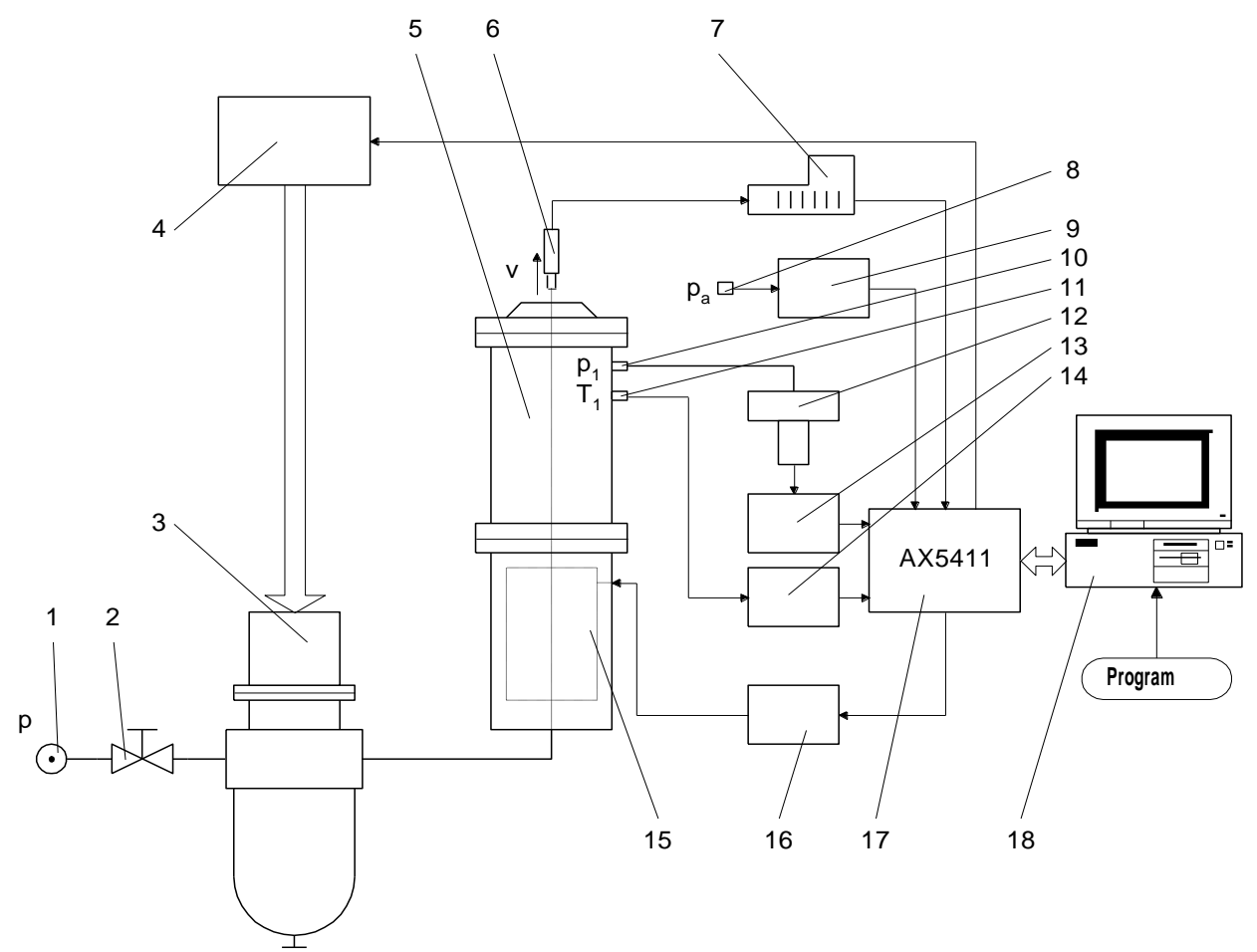

Figure 3: Set-up of the air-jet calibration installation of velocity transducers

Set-up of the air-jet calibration installation is shown in figure 3 and consists of: pressure source 1 , valve - 2, pressure regulator piloted with a stepper motor (MPP) - 3, which allows variation of air velocity at the exit of nozzle in the range $0 \div 50 \mathrm{~m} / \mathrm{s}$, MPP interface - 4, nozzle cylinder - 5, hot-element probe -6 , anemometer unit -7 , pressure transducer used to measure absolute pressure $\mathrm{p}_{\mathrm{a}}-8$, absolute pressure transducer interface -9 , pressure port - 10 , temperature transducer used to measure absolute settling chamber temperature $\mathrm{T}_{1}-11$, pressure transducer used to measure settling chamber gage pressure $p_{1}-12$, pressure transducer interface - 13, temperature transducer interface - 14, heating system - 15, heating system interface - 16, data acquisition board AX5411 - 17, PC - 18.

Velocity of the air at the exit of the convergent nozzle of calibration installation is determined with the relation:

$$
v_{2}=\varphi \sqrt{\frac{2 \chi}{\chi-1} R T_{1}\left[1-\left(\frac{p_{2}}{p_{1}}\right)^{\frac{\chi-1}{\chi}}\right]}
$$

where:

$$
\varphi=\frac{1}{\sqrt{1+\xi-\mu^{2} \varepsilon^{2}\left(\frac{p_{2}}{p_{1}}\right)^{1 / \chi}}}
$$

velocity

coefficient;

- $\xi$ local pressure loss coefficient (loss of pressure in the nozzle);

- $\varepsilon=A_{0} / A_{l}$ strangulation coefficient;

- $\mu=A_{2} / A_{0}$ contraction coefficient;

- $A_{1}$ inner area of cylinder;

- Ao area of nozzle;

- $A_{2}$ contracted area of the jet from the nozzle exit;

- $\chi$ adiabatic coefficient (for air $\chi=1.4$ );

- $R$ molar gas constant (for air $\mathrm{R}=287.04 \mathrm{~J} / \mathrm{kgK}$ );

- $T_{1}$ absolute settling chamber temperature; 
The inner diameter of the cylinder 5 is $d_{1}=64 \mathrm{~mm}$ and nozzle diameter is $\mathrm{d}_{0}=20 \mathrm{~mm}$, strangulation coefficient resulting $\varepsilon=0.0976$ and the velocity coefficient was estimated at $\varphi=0.835$ value.

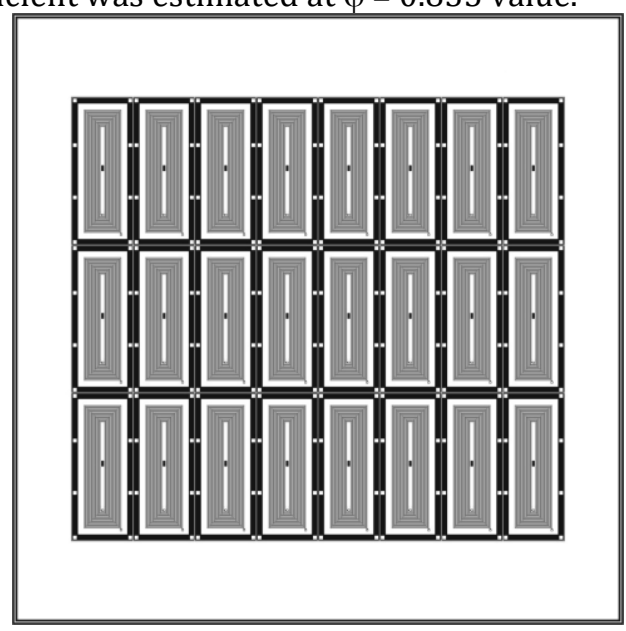

a)

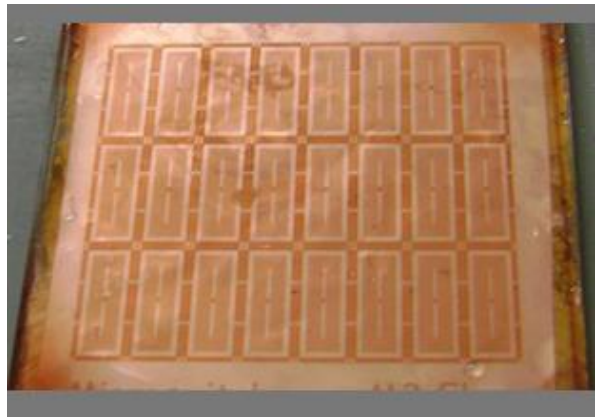

b)

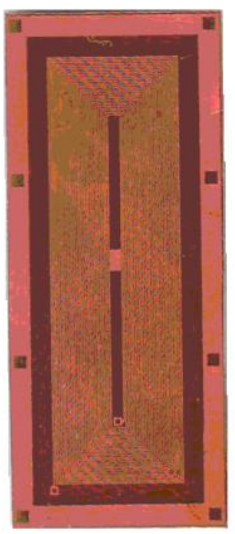

c)

Figure 4: The obtained structures: the photomask (a); photoetching structure (b); cutting individual structure (c)

\section{The Sensible Element Obtaining}

The thin film structure consisting in a spiral shaped (coiled) trace of copper, carried out on a flexible PCB (Printed Circuit Board) foil has been studied in this paper, as sensible element of a hot-film anemometer.

The dimensions of the structure are $19 \times 6 \mathrm{~mm}^{2}$, with lines and gaps of $50 \mu \mathrm{m}$ width and, respectively, $18 \mu \mathrm{m}$ height (thickness of the copper film), laminated on a polyimide substrate of $12.5 \mu \mathrm{m}$ thickness.

The configuration of this structure, presented in figure 4 , has been made through photoetching also known as selective chemical erosion using a photoresist mask.

The following stages have been performed: chemical polishing, photolithography, copper layer etching and photoresist mask removing. Finally, the thin film structure has been bonded with a thin and uniform layer of cyanoacrylate glue on a uncovered FR 4 PCB of $0.5 \mathrm{~mm}$.

\section{Experimental Results and the Sensor Characteristic Determining}

For the experiments was used a constant voltage anemometer with an adaptation circuit scheme given in figure 5, where $\boldsymbol{R}_{\boldsymbol{S}}$ is the sensor resistance and $\boldsymbol{R}_{\boldsymbol{L}}$ is the load resistance.

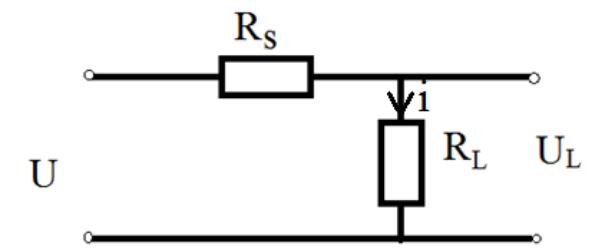

Figure 5: Scheme of the adaptation circuit

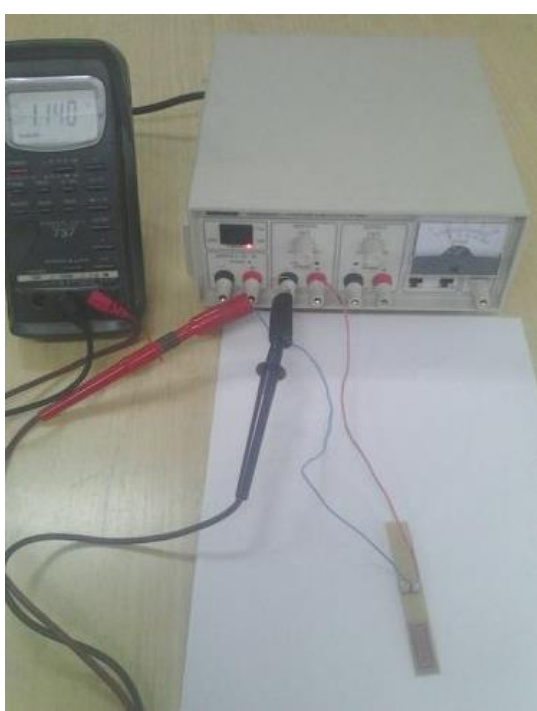

Figure 6: Electrical connection

The electrical connections of the sensor are presented in figure 6. The velocity transducer is mounted perpendicular to the direction of flow (fig. 7). Running the program of acquisition and data processing it allows determine the characteristic of constant voltage anemometer based on the increase in air velocity (in the range of $0-20 \mathrm{~m} / \mathrm{s}$ ). The calibration stand of hot sensitive elements, used in experiments, is presented in figure 8. Based on data resulted from calibration, the Table 1 has been completed (atmospheric pressure $\mathrm{p}_{\text {atm }}=101345 \mathrm{~Pa}$, air temperature $t_{\mathrm{atm}}=30{ }^{\circ} \mathrm{C}$ ). 
The sensor characteristic is presented in figure 9 .

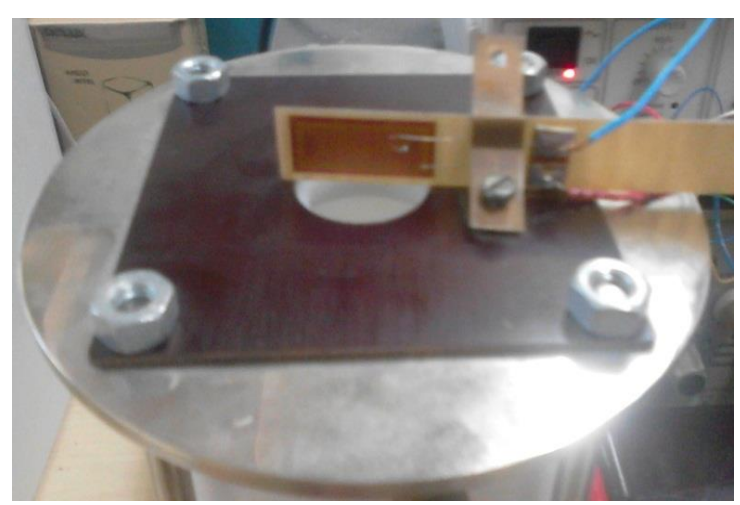

Figure 7: Fixing and alignment of the sensor in the flow direction of the fluid

Table 1. Calibration data

\begin{tabular}{|c|c|c|c|}
\hline No. & $\begin{array}{c}\text { Pressure } \\
\mathrm{p}(\mathrm{Pa})\end{array}$ & $\begin{array}{c}\text { Velocity } \\
\text { v2 (m/s) }\end{array}$ & $\begin{array}{c}\text { Voltage } \\
\mathrm{U}(\mathrm{V})\end{array}$ \\
\hline 1 & 0.057 & 0.827 & 1.317 \\
\hline 2 & 1.12 & 1.160 & 1.333 \\
\hline 3 & 1.34 & 1.268 & 1.352 \\
\hline 4 & 1.92 & 1.518 & 1.367 \\
\hline 5 & 4.59 & 2.347 & 1.382 \\
\hline 6 & 9.82 & 3.432 & 1.394 \\
\hline 7 & 15.38 & 4.296 & 1.402 \\
\hline 8 & 23.93 & 5.359 & 1.407 \\
\hline 9 & 79.46 & 9.764 & 1.420 \\
\hline
\end{tabular}

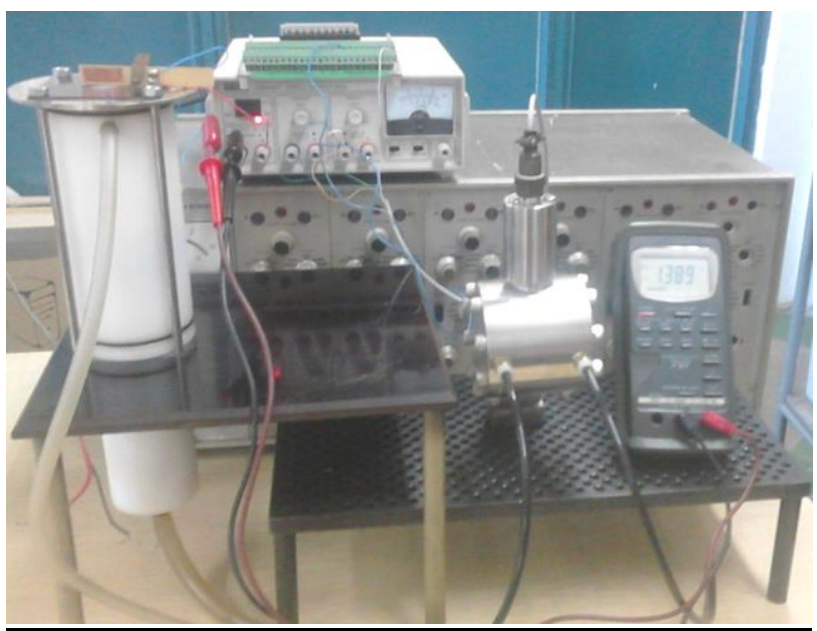

$\overline{\text { Figure 8: The calibration stand of hot sensitive elements }}$

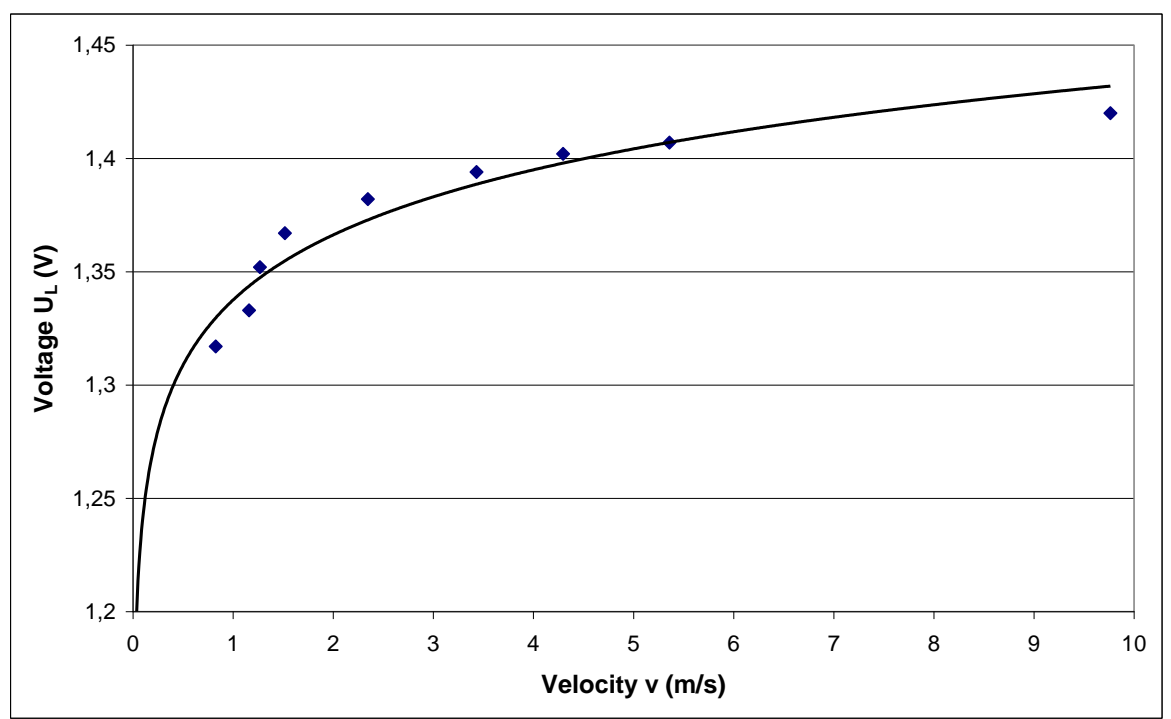

Figure 9: The voltage variation as a function of the fluid velocity

\section{Conclusions}

Use of a structure from copper thin film available as a laminated layer on a thin insulating polymer (polyimide) substrate, commonly employed in the printed circuit board (PCB) technology, was performed through microfabrication techniques and validated as sensible element of a constant voltage anemometer. For this purpose, an original installation was used to calibrate the new considered 
structure and the sensor characteristic was determined.

As future research, the experiments will be broadened considering also other thin film materials and orientations of the routes structure relative to the fluid flow direction.

\section{References}

[1] M. Laghrouche, A. Adane, J. Boussey, S. Ameur, D. Meunier, S. Tardu, A miniature silicon hot wire sensor for automatic wind speed measurements, Renewable Energy, Volume 30, Issue 12, October 2005, 1881-1896

[2] P. Liu, R. Zhu, R. Que, A Flexible Flow Sensor System and Its Characteristics for Fluid Mechanics Measurements, Sensors 2009, 9, 9533-9543; doi:10.3390/s91209533

[3] O.D. Osorio, N. Silin, J. Converti, Fabrication of hot-wire probes and electronics for constant temperature anemometers, Latin American Applied Research Pesquisa Aplicada Latino Americana = Investigación Aplicada Latinoamericana, July 2010

[4] N. R. Nagaiah, A. K. Sleiti, S. Rodriguez, J. S. Kapat, L. An, L. Chow, A Novel Design and Analysis of a MEMS Ceramic Hot-Wire Anemometer for High Temperature Applications, Journal of Physics
Conference Series 34 (2006) 277-282, DOI: 10.1088/1742-6596/34/1/046

[5] W. H. Ahmed, Experimental investigation of air-oil slug flow using capacitance probes, hot-film anemometer, and image processing, International Journal of Multiphase Flow 37 (2011) 876-887

[6] J.E. Hardy, T.E. McKnight, Reducing uncertainty in low flows for bench-top wind tunnels, Sensor Review, Volume 25, Issue 1, 2005

[7] C. A. Micu, C. Bucsan, L. Bogatu, Speed Transducer with Hot Sensing Element, RO 115301 B1 (1999) (in Romanian)

[8] http://www.taosystem.com/products/senflex/

[9] J. T. W. Kuo, L. Yu, E. Meng, Micromachined Thermal Flow Sensors-A Review, Micromachines (2012), 3, 550-573; doi:10.3390/mi3030550

[10] M. Schwerter, T. Beutel, M. Leester-Schadel, S. Buttgenbach, A. Dietzel, Flexible hot-film anemometer arrays on curved structures for active flow control on airplane wings, Microsyst Technol (2014) 20:821-829, DOI 10.1007/s00542-0132054-y

[11] T. Glatzl, S. Cerimovic, H. Steiner, A. Talic, R. Beigelbeck, A. Jachimowicz, T. Sauter, F. Keplinger, Development of Flow Sensors Realized with Printed Circuit Board Technology for Air Conditioning Systems, AMA Conferences 2015_Proceedings - SENSOR 2015, 309-314, DOI 10.5162/sensor2015/B7.2.

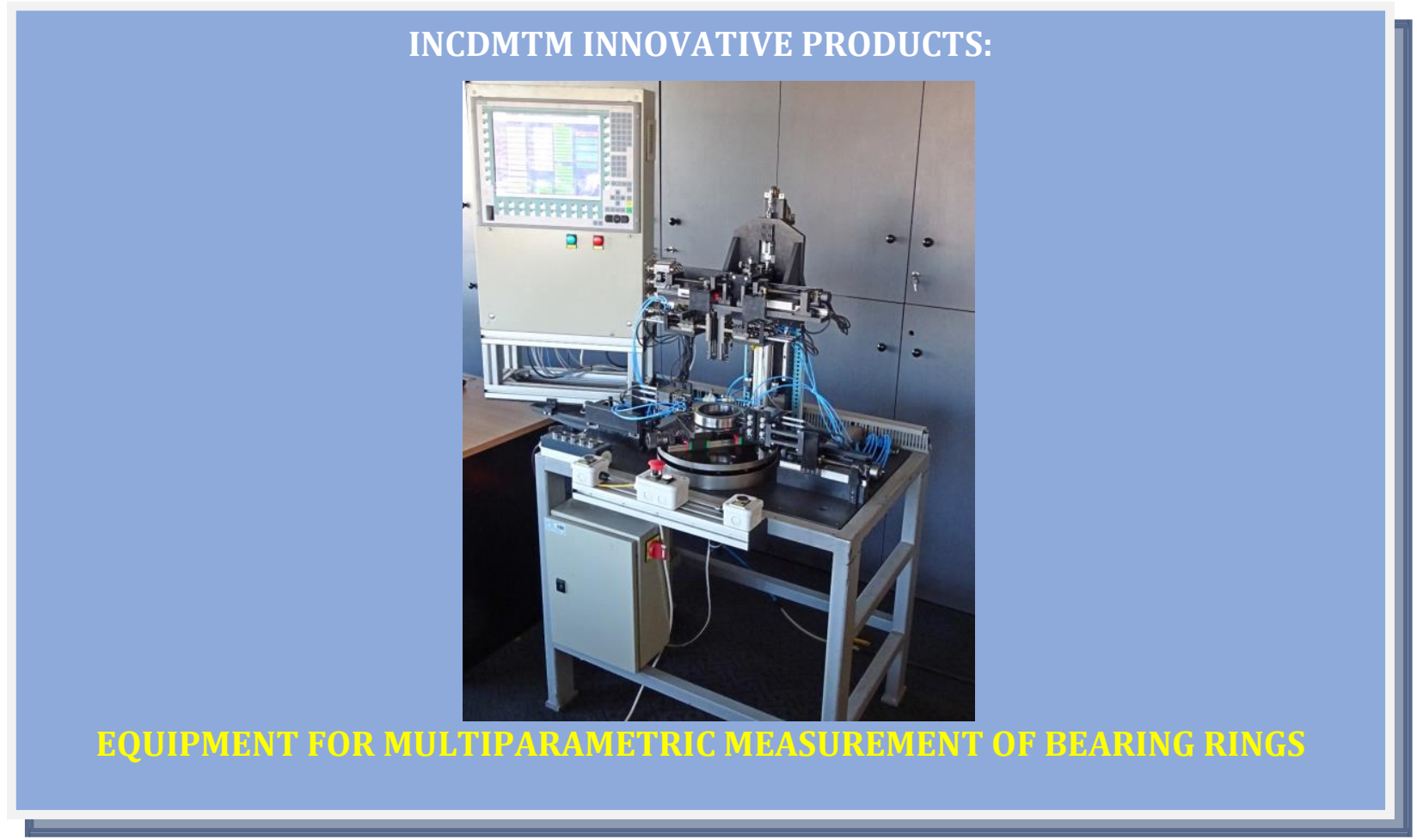

